\title{
CONTEMPORARY HERMENEUTICS AND THE ROLE OF THE SELF IN TRANSLATION
}

\author{
Amrollah Hemmat
}

Central Michigan University

\begin{abstract}
Hermeneutic investigations, which gained momentum by Schleiermacher in the early nineteenth century, seem to have led, by the close of the twentieth century, to a much deeper and more comprehensive understanding of the role of the translator. Various scientific and philosophical forces and moves have merged, reinforced each other, and ended in a confluence of theories which address the translator's concerns for the subjectivity of translation. This confluence is informed both by mainstream schools of thought such as Heidegger's and Gadamer's hermeneutic studies, Derrida's deconstructionism, Wittgenstein's adventures with language games, Michel Foucault's attention to reflexivity, and by more recent and less recognized works such as Gregory Bateson's systems and cybernetics thinking, Kenneth Burke's rhetoric and communication studies, Ervin Goffman's sociological studies, and finally Alton Lewis Becker's direct attempt in understanding the process of translation. This article synthesizes contemporary thought leading to such a hermeneutics understanding. It weaves together divergent approaches from different disciplines and draws an integrated perspective on the role of the translator. The author demonstrates that the long lived tension between traditional philology with its concern for the translator's fidelity to the original text and the contemporary hermeneutics view with its emphasis on the unique role of the translator as the co-creator of the text seems to have arrived at a relative reconciliation and ease through studies in self reflexivity.
\end{abstract}

\section{Resumen}

La investigación hermenéutica, impulsada por Schleiermacher a principios del siglo XIX, parece haber conducido, en los últimos años del siglo XX, a una concepción más amplia y profunda del papel del traductor. La confluencia de diversas fuerzas y corrientes científicas y filosóficas y su consiguiente refuerzo mutuo han dado lugar a la aparición de un conjunto de teorías que se ocupan de las inquietudes del traductor en torno a la subjetividad de la traducción. Este conjunto de teorías recoge 
influencias tanto de las principales escuelas de pensamiento, tales como los estudios hermenéuticos de Heidegger y Gadamer, la deconstrucción de Derrida, las aventuras de Wittgenstein con los juegos de lenguaje y la atención de Michel Foucault a la reflexividad, como de estudios más recientes y menos reconocidos, como los sistemas y el pensamiento cibernético de Gregory Bateson, los trabajos sobre retórica y comunicación de Kenneth Burke, los estudios sociológicos de Ervin Goffmann y, por último, el intento directo de Alton Lewis Becker por comprender el proceso de traducción. El presente artículo sintetiza las teorías contemporáneas que conducen a tal concepción de la hermenéutica y, al combinar enfoques divergentes pertenecientes a disciplinas diversas, ofrece una perspectiva integral del papel del traductor. El autor demuestra que la sempiterna tensión existente entre la filología tradicional, con su preocupación por la fidelidad al texto original, y la hermenéutica contemporánea, ferviente partidaria del traductor que goza del excepcional papel de co-creador del texto, parece haber alcanzado un estado de armonía y equilibrio relativos gracias a estudios sobre la auto-reflexividad.

Keywords: Translation. Hermeneutics. Self. Reflexivity. Deconstructionism.

Palabras clave: Traducción. Hermenéutica. El Yo. Reflexividad. Reconstrucción. 


\section{Introduction}

The dialogical nature of the text has been pointed out by Bakhtin and Gadamer among others. Becker's "languaging" theory helps us understand this dialogical nature of text and its implications for the translator. The translator or the reader gets engaged in a dialogue with the text, a dialogue which is spontaneous and unique to particular circumstances. The translator, therefore, moves beyond the limitation of the traditional philology and steps into the realm of hermeneutics, leaving the etic mode and adopting an emic perspective. Doing so, the translator's self plays a role in the process of translation which raises concerns for fidelity to the original text. To overcome such concerns of subjectivity, the translator engages in reflexivity, self evaluation, and examination of the assumptions taken for granted by the translator. A recursive process of defamiliarization and refamiliarization takes place, defamiliarization of the translator from the translator's own language game, awareness of the other's language game, and refamiliarization with his own language game, in light of the knowledge gained from the other's language game. This "learning by contrast" challenges the translator's most fundamental beliefs about truth and objectivity. Reflexivity makes one aware of the fact that one's point of view is often a constructed and subjective reality rather than an objective one based on the accurate observation of the other (the object). This is not, however, a final and conclusive answer for the problem of translator's subjectivity. As Babcock (1980: 11) quoting Spiegelberg (1969: 142) states "The only cure for subjectivity is reflexivity, which is 'more and better subjectivity, more discriminating, and more self-critical subjectivity, which will show the very limits of subjectivity." This article deals with the possibilities and limitations of the translator's self reflexivity in an attempt to avoid the subjectivity of translation.

\section{Dialogical nature of the text}

A dialogue normally takes place face to face between parties who see each other, at least virtually if not physically. It is usually a "live" event as in a debate broadcast on TV. The role of the context in the dialogical process has been studied by both social scientists and rhetoric analysts. In the reading of a text, although the author is not present there is a possibility of a "virtual" dynamic interaction between the reader and the author. The reader's state of mind and his or her culture provide a context for understanding and interpretation of the text. This context, as we will see, is not fixed. It is subject to change and in fact the text might play a role in changing it. This change in 
context in turn results in a different reading of the text. In that sense, there exists a mutual interaction between the reader and the text. The reader, or the community of readers, engage in a changing and dynamic interaction with the text. In particular, written texts that are emotionally charged such as political, religious and mystical texts provide a condition conducive to introducing a change in the reader and invoke various levels of involvement. Scriptures, patriotic texts and texts that invoke "larger social processes" are among such texts.

Bakhtin has pointed out to the dialogical nature of some text. (Emerson 1984: 18)

Dostoyevsky's novel is dialogic. It is constructed not as the whole of a single consciousness, absorbing other consciousnesses as objects into itself, but as a whole formed by the interaction of several consciousnesses, none of which entirely becomes an object for the other; this interaction provides no support for the viewer who would objectify an entire event according to some ordinary monologic category... and this consequently makes the viewer also a participant... everything in the novel is structured to make dialogic opposition inescapable.

There are others who also have observed the textual communication to be a dialogical process. Gadamer, according to Maranháo (1991: 245), was a pioneer in bringing our attention to the dialogical nature of text:

The metaphors of speaking and writing have exercised a true tyranny over the concept of communication, branding the speaker and the writer with the indelible mark of addressor and the listener and the reader as addressees. Gadamer began to break the shackles of this view conceiving dialogue as interaction between reader and text... The text beckons the reader and talks to him.

Becker (2000: 9) has applied the idea of the dialogical nature of the text to the task of translation and interpretation. In his studies of translation, Becker addresses this dialogical nature of the text by pointing out the difference between language and what he calls "languaging". Language is used for the code image, the conduit metaphor of communication. Languaging "combines shaping, storing, retrieving, and communicating knowledge into one openended process". Language is a model for communicating fixed messages that can be interpreted based on a fixed context. Languaging, on the other hand is "context shaping". "Languaging both shapes and is shaped by context" (Becker 2000: 9). Whereas language is based on universal rules, languaging shapes old texts into new context at the level of particularity. Each social dialogue, each encounter with a distant culture and each interaction with a text is a 
unique activity that engages both sides of communication: the speaker and the listener, the anthropologist and the native, the text and the reader.

This mutual engagement shapes the context in an ongoing and open ended basis. Each encounter is a particular and unique one. The translator and interpreter, therefore, should not rely on stereotypes and generic assumptions about a culture and a remote text. Instead, the interpreter participates in generation of meaning based on the particular incident of a communication encounter.

An awareness of this particularity and mutuality of communication is very important for the translator and interpreter. The interpreter is tasked to deconstruct his interpretation based on a recursive hermeneutic awareness of the contexts. By deconstruction, "Derrida's unfairly maligned term", in Becker's words, it is meant "a movement toward the source, which entails further deconstruction of the source into its many sources". (Becker 2000: 431). Knowing this, the translator or anthropologist would not see himself as the transmitter of the message but as a co-creator in the communication process. This makes him aware that his translation is only one particular interpretation and not the final one. Gadamer (1975: 118) asserts "In view of the finitude of our historical existence, it would seem that there is something absurd about the whole idea of unique, correct interpretation".

The outcome is not only the humility and openness of the translator but the production of a better translation. The better outcome is achieved through deconstruction of the translator's own prior text. Recognition of the subjectivity of the interpretation should not be taken as subjectivism or solipsism but as a means to providing a more objective result. As Gadamer (1975: 118) states, "the fact that the representation is bound to the work is not lessened by the fact that this bond can have no fixed criterion."

The particularity of each interpretation does not imply ignoring the context "since any meaningful activity is a conjunction of preexisting constraints (or rule, or structures, or laws, or myths) with the present, the unpredictable, particular now" (Becker 2000: 26). In this sentence Becker has hinted at different types of contextual relationships to the text (whether spoken text or written text), which he explains in various ways in Beyond Translation (Becker 2000: 25, 29, 186, 302-303, 381). In more detail these relationships are:

1. Structural: Relations of textual units (words, phrases, sentences, and larger units of the text) with each other within the text, which establishes hierarchy and coherence in the text. It is concerned with the relation of parts of the text to the whole text.

2. Generic: Relations of the text to prior texts. 
3. Medial: Relation of a text to medium such as sounding of words in a text.

4. Interpersonal: Relation of a text to participants in a text-act i.e. relationship of the author to both text and the hearers/readers of the text seen from the point of view of the author or from the points of view of the hearers/readers.

5. Referential: Relationship of a text to nature, the world one believes to lie beyond language.

6. Silential: Relationship of the text to unsaid and the unsayable.

Becker (2000:187) summarizes these six contextual relationships in this way: "The text has meaning because it is structuring and remembering and sounding and interacting and referring and not doing something else... all at once." The task of the translator is to evoke all original contextual relationships simultaneously. "The life of a text is in its weighting and balancing and counterbalancing of the terms and figures and in the conceptual drama they evoke" (Becker 2000: 187). To do this the translated text needs to be deconstructed and attuned across all contextual relationships. To the degree that the translator succeeds in doing so, he or she has produced aesthetic value and has remained faithful to the original (Becker: 309-312). Some contextual relationships, however, cannot be translated, such as sounding of words and syntactic shaping (Becker 2000: 306). However, the translator to a degree can compensate for this by generating aesthetic quality in creative ways such as deviating from the language norms and grammatical conventions. Such deviations can generate the desired context (Becker 2000: 322).

Becker (2000: 189) identifies two kinds of grammar. One is the conventional, rule governed, structural, and the other context shaping, pragmatic and relational. The former pertains to language and is universal; the latter pertains to languaging and is particular to the specific textual conversation. The translator's task is to "get closer to that particular text-in-context and see it as a reasonable and sane way of being in the world" (Becker 2000: 73). This, however, means a change in the translator/interpreter's perception in "a movement from an etic - an outsider's perspective - to an emic understanding, a more fully contextual understanding" (Becker 2000: 72).

Becker (2000: 92) also calls this a move from traditional philology to modern philology. Traditional philology is concerned with words, establishing the text itself, dictionary making, editing and initial translation. Modern philology is concerned with contextual questions. The former's primary concern is with universals and the rules of grammar while the latter's focus is on the particularity of the translator's task. The translator lives at the present 
and his or her job is to explicate the text or relate the text to the current context. The translator also needs to travel back in time and space and unravel the text's context. The interpreter and translator of ancient text makes a bridge between the past and the present by both contextualizing the past in the present and the present in the past.

Leeds-Hurwitz (1989: xvii) suggests that "the traditional division of the field of communication into interpersonal, organizational, and mass communication may not always be the most appropriate way to divide up the world". If we replace the conduit model of communication with a "participant-centered" model, the division between interpersonal and textual fields of communication gets blurred. Some contextual elements of communication can play similar roles in two different modes of communication: conversational and textual. This similarity becomes particularly strong when the text is not a scientific or factual one, but rather a metaphorical text. Poetry, spiritual, and mystical texts of various traditions are among written texts that develop and maintain a dynamic dialogical relationship with the reader. Such a dynamic relationship entails introducing a change in the reader's context i.e. the reader's culture and state of mind.

Awareness of the dynamic nature of interaction between the text and the reader is crucial for proper interpretation and translation of these texts since it reminds the translator to avoid rendering a concrete and non-ambiguous version of the text that reduces the possibility for a dynamic interaction with the reader. Also, the translator becomes aware of his or her own subjective and dynamic relationship with the text both as a reader and as the interpreter of the text. As an interpreter of the text, the translator becomes reflexively aware of the role his or her "self" plays in interpreting a text that has no predetermined, fixed meaning. "Meaning is to be observed in the relations of an organism with its particular environment", John Dewey states (Becker 2000: 380). The particular environment or particular context is what the contemporary philologist brings into the equation in addition to the prior text.

\section{Reflexivity and self in translation}

Becker's simple statement that everything said is said by someone has deep implications for understanding the process of translation. "Someone" here refers to the particularity of communication, and similarly, to the particularity of translation. The translator's self, prior text, cultural and language patterns and creativity all play an important role in translating an ancient text in the same language or translating across languages. 
The conduit metaphor of communication is inadequate as a model for translation as it is problematic for explaining communication processes in general. The text being translated is not a set of fixed and predetermined facts that can be transferred to another language. In the process of translation, the translator's self plays a role in defining what the text is and means.

The translator needs not only to be aware of and acknowledge the role which his or her "self" plays in defining and interpreting the text, he or she should actively deconstruct and reconstruct the translated work through a "recursive hermeneutic process" (Steier 1995: 78) in order to achieve the maximum possible level of fidelity to the text. Becker warns us not to mix this recursive deconstruction with subjectivity or relativism:

Self-correction of this sort, the self-consciousness of one facing a text in a distant language, should not be confused with subjectivism, as some have suggested, for it is the opposite- a respect for another voice not an obsession with one's own (Becker 2000: 138).

The translator's "self reference," or awareness of the role of the self in the process of translation, by itself alone, is problematic and can even be crippling. Rather than solely "closing the circle," Steier points out the need "[...] to open outward toward other forms of this self-expression, and toward an awareness of multiple conversations" (Steier 1995: 84). The translator needs to take into account alternative ways of understanding the self and the other. The philologist's task is to evoke all possible frames. "Philology is the study of other frames," in Becker's words (Steier 1995: 372). Philology is therefore a meta activity. It requires transcending one's language game and cultural frames. This is not a simple task. Becker (2000: 140) calls such a hermeneutic endeavor utopian. Not only are such deconstruction and self-correction utopian, even "textual criticism", with its reliance on dictionary and grammar and its objective of achieving genuine text, is utopian.

Becker (2000: 137) distinguishes between what he terms "primary philology" and "secondary philology". Primary philology is concerned with establishing the text itself through interpretation of vague and difficult words, dictionary making, editing and translation. It involves textual criticism. Secondary philology or modern philology is concerned with the context questions. It goes beyond translation and is concerned with the modern hermeneutics interpretation.

The modern philologist begins to fear he may be gazing at the mirror of his own imagination. Surely what is modern in modern philology is to ascertain self-consciousness about the observer along with the observed. (Becker 2000: 92) 
In traditional philology or primary philology such a concern with the observer was rare and even considered as self-indulgence. It was deemed disloyal to the text for the translator to fully expose the deepest biases of his own culture (Becker 2000: 92).

\section{The double bind theory}

Gregory Bateson's (1972: 271-278) "double bind" theory can help us understand the translation process in that it explains the dynamics of reflexivity and a higher level of learning. A "double bind" is a situation in which one is faced with contradictory and opposite messages and does not have a way to get out of the situation. This paradoxical situation can cause one to reframe the situation and achieve a higher level of learning. Every communication according to Ortega is a paradoxical situation since:

- Every utterance is deficient in that it says less than what it wishes to say.

- Every utterance is exuberant in that it says more that it plans (Becker 2000: 298).

This is also true for translating a distant text. Translation and interpretation of distant text (in time, space, or both) is both deficient and exuberant since the translator ends up saying more than what the original text said and missing some of it. This is particularly clear when the translator translates metaphors and allegorical language of a distant culture into metaphoric language in the target language. This creates an inescapable "double bind" situation for the translator. The paradoxical characteristic of the translation makes it reflexive since the translator is engaged in an impossible task, a "double bind" which leads to reflexivity on one's own culture and the culture of the other. This should lead to a higher level of understanding, which is achieved through the process of recursive hermeneutic self-correction.

Glossy translation, which is the outcome of primary philology, is not the end point, the final outcome of philological endeavor. "Rather, it is the starting point, the beginning of moving back, looking back, toward the source of the translation" (Becker 2000: 18). The translator needs to move back to identify deficiency and exuberance in his work. Hence translation is a reflective process. "Self-correction of this sort, self-consciousness of one facing a text in a distant language" (Becker 2000: 138) is a reflexive process.

Etic understanding of the text is an outsider's understanding. Emic understanding of the text involves a reflexive process that an outsider adopts in order to develop an insider's understanding: "A deliberate process of foregrounding dissimilarity and self-consciously, methodically correcting the exuberance and deficiencies of one's outside understanding" (Becker 2000: 
233). This is a methodical and systematic reflexive activity. Reflexivity in this case is not based on theories. If one tries to rely on the metalanguage of theory one fails, since theories are products of one's own culture. Instead, particular texts of particular times and particular places need to be analyzed to arrive at a self-consciousness about our own traditions, theories, and cultural assumptions and move toward an emic understanding (Becker 2000: 238). Translation of a particular text, therefore, can be utilized for developing a reflexive understanding of our relationship to, and understanding of "the other." This is a nonuniversalist, relativistic approach to language that Kenneth Pike has called "emic" (Becker 2000: 254).

The modern philologist contextualizes by going beyond the surface message and digging into the message about the message. This reflecting the message back into itself and looking at it in terms of its own context is a reflexive activity (Becker 2000: 27). It is a reflexive process since "each way that text relates to its context [...] defines a way of interpreting the world." This is not an arbitrary interpretation of the world, however (Becker 2000: 58). Translation is something that needs to be deconstructed "in a movement back toward an understanding of the original text, the source of translation, in order to correct the exuberances and deficiencies of the translation" (Becker 2000: 138).

Philology is always a secondary language act: Language about language, or as some call it - metalanguage. It might be called logology, following Kenneth Burke, who defines logology simply as 'words about words'. (Becker 2000: 372)

\section{Bridge building}

In his analogy of research as a translation process, Steier explains the bridge building characteristic of translation. Becker points out the salient characteristic of such a process as "moving back and forth" between the two "language game" (in Wittgenstein's language) domains and being aware of such reflexive activity (Steier 1991: 176).

This would be a process of bridge building requiring repeated "defamiliarization" and "refamiliarization" of the translator: defamiliarization of the translator from the translator's own language game, awareness of the other's language game, and refamiliarization with his own language game in the light of the knowledge gained from the other's language game (Steier 1991: 176). To achieve this, the translator needs to distance himself from himself. We can only observe ourselves if we distant ourselves from ourselves (Disalvo 1980: 23). "Authentic self knowledge requires experience of, and reflection of a 
tangible reality clearly distinguished from the self" (Disalvo 1980: 23). If one only focuses on one's self, the result would be narcissism; therefore, one also needs to study "the other".

Translation that takes place by constructing "the world of the other for the other" without the full awareness of, and respect for different language games is exemplified as reflexivity in the small circuit sense by Steier. Instead, Steier calls for "an attempt to see a world or worlds in other's terms". He describes this further: "translation requires an awareness that there is another conversation that is perfectly legitimate and fits (and indeed constitutes) the world of its participants." This, Steier calls the long circuit sense of reflexivity.

Reflexivity makes one aware of the fact that one's point of view is often a constructed and subjective reality rather than an objective one based on the accurate observation of the other (the object). Karp and Kendall (1982: 250) describe good fieldwork as requiring "turning the anthropological lens back upon the self and coming to understand that one's own social realities are simply one society's construction rather than a given in nature". This poses challenges to one's most fundamental beliefs about truth and objectivity. "Learning by contrast" is a term anthropologists use for a learning that takes place as a result of the shock one feels when faced with a reality different from one's own constructed reality (Karp \& Kendal: 262). Learning by contrast can lead to further reflexivity, learning and growth. We can place ourselves in the framework of "the other" to develop and examine a new image of ourselves. Grounding ourselves in another situation lets us examine our image in a frame that is different than what we are used to.

Grounding of self in other's frame, however, can itself be motivated by our own self-image. Fernandez (1980: 28) placed himself in the royal Chambers of Phillip the Fourth in Prado's duplication of mirrors: "the mirror should show the king and queen in every man." He recounts the experience of a Fang native of Western Africa, during the initiation ritual when staring at a mirror for hours and under the influence of the psychedelic herb, eboga; "his or her face or an ambiguous mark becomes transformed into the significant other with whom the religion or curing cult is seeking to come in contact." Similarly, to be initiated in our culture we need first to be able to see our cultural heroes in ourselves. We should identify ourselves with our significant ancestors. Pictures of Abraham Lincoln "will cause in us reflections upon the essential virtues of the Republic" (Fernandez 1980: 34).

"The other" that we ground ourselves in, therefore, might be selected and constructed by our assumptions about ourselves, the way we see ourselves or we want to see ourselves. This would be only a reflection of our own image 
back to ourselves. It does not have a reflexive quality. It is not an understanding of "the other" that would help the understanding of "the self". What we do as anthropologists is:

holding a mirror up to man in which, by seeing ourselves strangely (or darkly) in another culture, we can discover the essence of our humanity if not the possibilities of its perfection. The more modern notion [...] is that the mirror we have been holding up first of all reflects ourselves, the makers and manipulators of the mirror. (Fernandez 1980: 34)

According to Gadamer: "Every translation is at the same time an interpretation" (Weinsheimer \& Marshal 1985: 384). The translator makes sense of and interprets the text and translates it into the context of the new language. Ricoeur (1974: 16-17) considers all interpretation, "explicitly or implicitly, self-understanding by means of understanding other", and "it is thus the growth of his own understanding of himself that he [the exegete] pursues through his understanding of the other". In this process, one needs to be careful not to merely observe a reflection of one's own self in the other. Otherwise, no growth would take place.

It is not easy to be aware of such an often unconscious trapping because one's understanding and interpretation of self and the other is deeply rooted in one's own language and culture. Steier identifies a "circularity" between interpretation and language, a "mutually defining relationship" on which many daily activities are based. Interpretation is based on what we have previously learned, what is embedded in our language. Language, on the other hand, is learned by interpretive activities. This circular relationship also exists between our daily experiences and our language. Our individual experiences are "socially constructed, rooted in language activities", and the possibilities for those language activities are in turn provided by our experiences (Steffe \& Gale 1995: 71). Anderson and Cissna (1996: 88) make a similar point: "Humans don't 'use' language as much as they 'live within it', subject to its conditions."

\section{Questions for the translator}

Knowing the often unconscious role of the self in translation, some important questions for the translator are: How can a translator avoid the pitfalls of subjectivism, solipsism, and narcissism? What are the standards for fidelity to the original text? To avoid subjectivity, how much can the translator rely on the historical context of the text being translated? We will deal with this last question first. 
Historical context is a tool traditionally adopted by the interpreters in order to understand the text correctly. This, however, does not make the task easier. As Mailloux (1990: 127) states:

Any reading assumes some status 'within the power relations of a historical community', meaning that most interpretations involve political interests, consequences, coercion, persuasion, and rhetoric.

History is not a collection of undeniable and fixed facts. It is constructed and subject to interpretation. "The past can be endlessly argued over and argued with, it can itself be a battleground or it can be raided, rebuilt, and perverted for any number of human purposes" (Gronbeck 1998: 49). The translator therefore, whether acknowledging it or not, has a degree of freedom in the interpretation of the historical context of what is being translated.

Considering contemporary theories of hermeneutics, the translator has the choice, and perhaps is even obligated, to step totally beyond the boundaries of history. He or she can translate what at one time had a specific meaning in history to another thing since at this time the alternative meaning is a more appropriate one. "The meaning of what is said is, when we understand it, quite independent of whether the traditional text gives us a picture of the author and of whether or not we want to interpret it as a historical source" (Weinsheimer \& Marshal 1985: 392). This point of view is representative of the contemporary definition of hermeneutics.

In Truth and Method, regarding a work of art Gadamer points out how the "work's claim" can be different than what the work is as a historical text and poses the important question of "whether one accepts the work's claim to meaning or simply regards it as a historical document that one merely interrogates". Gadamer's example of a portrait explains his point well:

For the portrait does not say who the person portrayed is, but only that it is a particular individual (and not a type). We can 'recognize' who it is only when the person portrayed is known to us, and be sure only when there is a title or some other information to go on. (Gadamer 1975: 140)

According to Gadamer, "the historian will seek out every element that can tell him something of the past, even if it counters the work's claim to meaning". Giving the example of a poem, Gadamer (1975: 140) further asserts that "someone might explain to us the particular historical context, but this would be only secondary for the poem as a whole. He would be only filling out the meaning that exists in the poem itself".

Hermeneutics was traditionally about understanding the text and in particular the sacred text as it was originally written. However, a trend of thought that started with Schleiermacher changed the direction of hermeneutics. 
According to contemporary hermeneutic views, the meaning attributed to the translated work needs to be detached from what historically appears to be the real intent, or the one and only intent of the original author. "Reconstruction" of the past is not adequate. Rather, "integration" of it with the present and "thoughtful mediation with contemporary life" is required (Gadamer 1975: 157-161). In other words, "the understanding of something written is not a repetition of something past but the sharing of a present meaning" (Weinsheimer \& Marshal 1985: 392).

Considering contemporary hermeneutic assumptions, the role of the translator's self becomes important because of its essential contribution to "contextualization of past into present" (using Becker's terminology). This is especially true when translating poetic and other texts that heavily utilize figurative language. The purpose of the figurative language is to open up opportunities for various interpretations. Figurative language in particular evokes the reader's participation and in a sense engages the reader in a conversation with the text. Mystical texts, like poetry, engage the reader in different conversations at different times. Even the same reader obtains a new level of enlightenment at different stages of life or under different mental conditions. These texts are like two-way conversations. Conversation according to Gadamer cannot be "conducted". Genuine conversation is out of the partners' control. It has a "spirit of its own" and "allows something to emerge". Therefore, rather than conducting a conversation, "we fall into conversation" (Weinsheimer \& Marshal 1985: 383). Mystical texts for instance engage the readers in unexpected experiences that transcend the limits of history and time. They stimulate new interpretations forever. Each reader plays a unique role in this process and arrives at an interpretation appropriate for his or her own self.

The translator cannot be viewed as von Foerster's trivial machine translating a specific cause (source language input) to a specific effect (target language output) with a one-to-one relationship between the input and the output. If that was the case, translation process would have been a deterministic system i.e. analytically determinable, with predictable output (von Foerster 1991: 69). Although there is logic to the careful choices a conscious and responsible translator makes, the outcome is certainly not predictable. In that sense the process of translation is similar to a non-trivial machine-transcomputational in that the outcome cannot, for all practical purposes, be calculated. In non-trivial machines the input/output relationship is determined by the machine's previous operation, which has framed the next operation for a specific response. In the interpretation of text we come across cases where 
our interpretation of one word frames the interpretation of a subsequent word and that interpretation in turn informs the interpretations of the words or sentences which follow. Mathematically the number of possible interpretation choices can become so high that the outcome cannot be easily predicted.

Depending on the text, the application of the contemporary concept of hermeneutics can be straightforward or problematic. This contemporary view, as mentioned earlier, is that "the understanding of something written is not a repetition of something past but the sharing of present meaning" (Weinsheimer \& Marshal 1985: 392). This can be applied to mystical texts, poetry and the like with ease, but applying it to texts such as religious laws is problematic. It would mean that the interpreter can unconditionally revise religious tenets based on his or her understanding of the text influenced by requirements of the translator's time and culture.

Even in the case of mystical texts and poetry, one cannot categorically ignore historical context. Gadamer, for instance, does not eliminate the need to go back to history nor does he assign primary importance to it: "To understand it [literature] does not mean primarily to reason one's way back into the past, but to have a present involvement in what is said" (Weinsheimer \& Marshal 1985: 391). By this Gadamer perhaps means history needs to be hermeneutically reconstructed relating it to the present. Becker calls this contextualizing the past into the present (Weinsheimer \& Marshal 1985: 51).

Another important question that needs to be asked by the translator is the subjective role his or her self plays in the selection of a specific meaning, at the expense of eliminating alternative meanings. The translator often needs to choose from many possible interpretations. Gadamer writes: "Translating is like an especially laborious process of understanding, weighing and balancing possibilities, the translator will seek the best solution - a solution that can never be more than a compromise". Selection is a tricky and difficult task especially if we consider the role that the translator's personal biases might play.

At times the translator is faced with an overwhelming number of choices in the interpretation of text. The number of interpretation choices can become manageable by taking into consideration the history, culture, and the prior text that informed the text. These factors eliminate some interpretation possibilities and make others more promising. This at first seems to be in conflict with Gadamer's statement that: "Understanding is certainly not concerned with understanding historically", i.e. reconstructing the way the text came into being (Weinsheimer \& Marshal 1985: 388). Gadamer's statement is, however, profound considering the objective of translation. Generally, if translation is to benefit the reader, its historicity cannot have priority. In most 
cases, the extent to which the readers benefit from literature will be diminished by focusing on why and how the text was composed. What is more important is how the reader relates to the work within the scope of the reader's particular time and concerning the culture the reader lives in. This makes the translator's personal contribution essential.

The effect of different interpretations of the text at times may be subtle but nonetheless important. The translator as an interpreter "highlights" some aspects of the text in favor of others. According to Gadamer, "translation, like all interpretation, is a highlighting. A translator must understand that highlighting is part of his task" (Weinsheimer \& Marshal 1985: 386). This highlighting is influenced by the translator's culture, tradition, and point of view in spite of the translator's reliance on the history and cultural environment of the text.

A level of highlighting takes place during the reconstruction of the underlying text so that the reconstructed text is meaningful in the target language. "When we try to translate from one language to another and from one system of categories to another, we discover that categories slip and slide, never matching perfectly" (Bateson 1994: 58). Some aspects that were not depicted or highlighted in the original language need to be constructed or highlighted in the target language to compensate for what Becker calls "silence" in the original language (Becker 2000: 6). Conversely, some other aspects emphasized in the original need to be discounted and de-emphasized. In other words, the translator is faced with "exuberances" and "deficiencies" of the original text.

\section{Conclusion}

All efforts for assuring fidelity and accuracy - reconstruction of history, compensation for exuberances and deficiencies, careful selection and highlighting - are informed by the translator's self. The translator, like the anthropologist, often unconsciously assumes a power position and places himself in a superior position compared to the native or to those whose text is being translated. "Power and interests are dimensions of all social relationships" according to Karp and Kendall (1982: 264), and Max Weber goes as far as arguing that "the beliefs and values as components of social action act as no more than switching devices, directing action into one or another path in a course to a pre-existing goal".

The translator, through the process of translation, says something even if he or she is not willing or even aware of voicing a personal opinion. Therefore, with all concerns for objectivity, a degree of subjectivity seems to be 
unavoidable. Perhaps Babcock (1980: 11), quoting Spiegelberg, has the ultimate remedy to this paradoxical situation: "The only cure for subjectivity is reflexivity, which is 'more and better subjectivity, more discriminating, and more self-critical subjectivity, which will show the very limits of subjectivity'[...]". Although reflexivity is by itself a subjective activity, it seems to be more of a solution than a problem. Even though the role of the translator's self cannot be eliminated, it can be examined, shaped, systematized, and even minimized when desired.

\section{References}

Anderson, Rob \& Kenneth N. Cissna. (1996) "Criticism and Conversational Text: Rhetorical Bases of Role, Audience, and Style in the Buber-Rogers Dialogue." Human Studies 19:1. pp. 85-118.

BABCOCK, Barbara. A. (1980) "Reflexivity: Definition and Discrimination." Semiotica 30:1/2. pp. 1-14.

BATESON, Gregory. (1972) Steps to an Ecology of Mind. Chicago: The University of Chicago Press.

BAteson, Mary Cay. (1994) Peripheral Visions: Learning Along the Way. New York: Harper Collins Publisher.

BECKER, Alton. L. (2000) Beyond Translation: Essays Toward a Modern Philology. Ann Arbor: University of Michigan Press.

DisAlvo, Marilyn. (1980) "The Myth of Narcissus." Semiotica 30:1/2. pp. 15-25.

EMERSon, Caryl (tr.) (1984) Mikhail Bakhtin, Problems of Dostoevsky's Poetics. Theory and History of Literature Series, vol. 8. Minneapolis: University of Minnesota Press.

FernandeZ, James W. (1980) "Reflections on Looking into Mirrors." Semiotica 30:1/2. pp. 27-39.

GadAMER Hans-Georg. (1975) Truth and Method. Second Revised Edition. Translation revised by Joel Weinsheimer and Donald G. Marshall. London: Continuum Publishing Group.

GRONBECK, Bruce E. (1995) "The Rhetorics of the Past: History, Argument and Collective Memory." In: Turner, Kathelin J. (ed.) 1998. Doing Rhetorical History: Concepts and Cases. Tuscaloosa: University of Alabama Press. pp. 47-60.

KARP, Ivan \& Martha. B. Kendall. (1982) "Reflexivity in Field Work". In: Secord, Paul F. (ed.) 1982. Explaining Human Behaviour. Beverly Hills: Sage Publications. pp. 249-273.

LeEdS-HuRWITZ, Wendy. (1989) Communication in Everyday Life: A Social Interpretation. Norwood: Ablex Publishing Corporation. 
MaillouX, Steven. (1990) "Interpretation". In: Lentricchia, Frank \& Thomas McLaughlin (eds.) 1990. Critical Terms for Literary Study. Chicago: Chicago University press. pp.121-134.

MARANHÁO, Tullio. (1991) "Reflection, Dialogue, and the Subject". In: Steier, Frederick. (ed.) 1991. Research and Reflexivity. London: Sage Publications. pp. 235-249.

Ricoeur, Paul. (1974) The Conflict of Interpretations. Chicago: Northwestern University Press.

SPIEGELbERG, Herbert. (1966) "How Subjective is Phenomenology?" In: Natanson, Maurice (ed.) 1966. Essays in Phenomenology. The Hague: Martinus Nijhoff. pp. 137-143.

STEFFE, Leslie P. \& Jerry Gale (eds.) (1995) Constructivism in Education. Hillsdale, NJ: Lawrence Erbaum.

STEIER, Frederick. (1995) "From Universing to Conversing: An Ecological Constructionist Approach to Learning and Multiple Description". In: Steffe, Leslie P. \& Jerry Gale (eds.) 1995. pp. 67-84.

STEIER, Frederick. (1991) "Reflexivity and Methodology: An Ecological Constructionism”. In: Steier, Frederick (ed.) 1992. Research and Reflexivity. London: Sage Publications. pp 163-185.

VON FOERSTER, Heinz (1991) "Through the Eyes of the Other". In: Steier, Frederick (ed.) 1992. Research and Reflexivity. London: Sage Publications. pp. 63-75.

WeInSHEIMER, Joel C. \&. Donald G. Marshall (trs.) 1985. Gadamer's Hermeneutics: a Reading of Truth and Method. New Haven: Yale University Press. 